Jurnal Pemberdayaan: Publikasi Hasil Pengabdian kepada Masyarakat

Vol. 4, No. 3, Desember 2020, Hal. 237-244

ISSN: 2580-2569; e-ISSN: 2656-0542

DOI: https://doi.org/10.12928/jp.v4i3.1281

\title{
Analisis dampak pelatihan microcontroller berbasis arduino di SMA Perguruan Buddhi
}

\author{
Jacob F. N. Dethan, Benny Daniawan, Rino, Susanto Hariyanto, Ardie H. Wijaya, Ramona D. \\ Safitri, Desiyanna Lasut, Rudy Arijanto, Fennita \\ Fakultas Sains dan Teknologi, Universitas Buddhi Dharma \\ Jl. Imam Bonjol no 41. Karawaci, Tangerang, Banten 15115. \\ Email: jacob.dethan@ubd.ac.id
}

\begin{abstract}
ABSTRAK
Perkembangan teknologi saat ini yang telah mencapai era industri 4.0 mendorong terjadinya perubahan gaya hidup manusia yang lebih tergantung dengan teknologi. Untuk itu, siswa SMA harus diberikan pemahaman terkait perkembangan teknologi. Salah satu cara yang dapat ditempuh adalah dengan mengadakan pelatihan terkait sistem otomasi yang dalam hal ini dapat diajarkan menggunakan microcontroller Arduino. Dalam pelatihan yang telah diselenggarakan, kami melihat minat besar yang muncul dari peserta pelatihan yang dapat dinilai dari hasil pengisian kuesioner yang diberikan ke peserta. Dari maksimum 152 responden, 61,6\% peserta menyatakan bahwa pelatihan ini menarik dan 30,5\% menjawab sangat menarik. Kemudian, 57,9\% responden menjawab pelatihan ini bermanfaat dan $40,1 \%$ menyatakan bahwa pelatihan ini sangat bermanfaat. Selain itu, kami juga mengadakan survei terpisah untuk melihat minat siswa dari jurusan IPS dan secara mengejutkan kami temukan bahwa 65,3\% siswa IPS menyatakan bahwa pelatihan ini menarik dan 29,2\% menyatakan sangat menarik. Mayoritas siswa IPS juga menjawab bahwa pelatihan ini bermanfaat $(58,3 \%)$ dan sangat bermanfaat (40,3\%). Sehingga, kami menemukan adanya peningkatan minat siswa untuk mempejari sistem otomasi secara signifikan karena 90,7\% dari total peserta belum pernah mempelajari Arduino sebelumnya.
\end{abstract}

Kata kunci: microcontroller, Arduino, sistem otomasi, siswa

\begin{abstract}
The development of technology that has reached the industrial era of 4.0 leads to the change of human lifestyle that is more dependent to technology. Thus, senior high school students must be taught about the development of technology. One of the ways that can be taken is through training about automation system which in this case can be taught using Arduino microcontroller. After conducing this training, we found great amount of interest shown by the trainees that can be judged based on the results of the survey that was given to the trainees. From maximum of 152 respondents, $61.6 \%$ trainees stated that this training is interesting and $30.5 \%$ declared that it is very interesting. Then, $57.9 \%$ respondents said that this training is useful and $40.1 \%$ stated that it is very useful. Besides, we also conducted separate survey to assess the interest of students with social science background and surprisingly we found that $65.3 \%$ students declared that this training is interesting and $29.2 \%$ said that it is very interesting. Majority of these students also answered that this training is useful (58.3\%) and very useful (40.3\%). Therefore, we found a significant increase of the interest from the students to study automation system since $90.7 \%$ of the total trainees have never studied Arduino before.
\end{abstract}

Keywords: microcontroller, Arduino, automation system, students

\section{PENDAHULUAN}

Revolusi industri 4.0 telah semakin menyadarkan masyarakat akan pentingnya pemahaman tentang teknologi. Salah satu bidang yang sangat dominan dari perkembangan teknologi adalah bidang sistem otomasi. Untuk itu, pemahaman tentang otomasi sudah harus 
sejak dini diperkenalkan kepada pelajar terutama pelajar di tingkat SMA/SMK. Salah satu SMA yang belum mengajarkan pelajaran ataupun kegiatan ekstrakurikuler terkait sistem otomasi adalah SMA Perguruan Buddhi Tangerang.

Beberapa peneliti sebelumnya telah menyarankan akan pentingnya pelajaran sistem otomasi untuk disertakan di dalam kurikulum di sekolah menengah (Wong et al., 2018). Secara spesifik, Arduino juga disarankan untuk diperlajari (Martín-Ramos et al., 2018). Tapi, siswa SMA Perguruan Buddhi Tangerang sampai saat ini belum pernah mendapatkan pelajaran terkait sistem otomasi dengan materi yang memadai. Oleh karena itu, peneliti mengadakan pelatihan Ardunio untuk siswa SMA baik itu dari jurusan IPA maupun IPS dari kelas XI sampai kelas XII.

Arduino dipilih sebagai microcontroller yang diajarkan karena Arduino menawarkan beberapa keunggulan seperti murahnya harga beli (Boulogne, 2019), mudah digunakan dan memiliki daya tahan yang baik (Sai et al., 2019). Selain itu, pengkodean Arduino dilakukan berbahasi bahasa $\mathrm{C}$ sederhana. Sehingga, siswa SMA Perguruan Buddhi Tangerang diajarkan menggunakan microcontroller yang mudah dipelajari dengan harga yang terjangkau dan pelatihan ini menawarkan cara belajar sistem otomasi yang mudah dipejari. Selain Arduino, terdapat juga controller yang digunakan di dunia industri seperti programmable logic controller. Tapi, harganya jauh lebih mahal dibandingkan dengan Arduino sehingga belum tepat untuk diajarkan untuk siswa SMA.

Materi yang disampaikan mencakup perintah-perintah dasar yang digunakan untuk pengkodean Arduino. Siswa juga diajarkan untuk merangkai rangkaian dasar LED yang digunakan sebagai media untuk mengamati perubahan yang terjadi pada kedipan LED ketika program yang dibuat dimodifikasi dengan menggunakan berbagai perintah dan logika dalam pemograman berbasis Arduino. Percobaan diharapkan dapat memberikan manfaat dan kemudian dapat dikembangkan seperti aplikasi yang dijelaskan dalam penelitian sebelumnya (Shruthi and Akhil, 2019).

\section{METODE}

Pelatihan ini dilaksanakan selama 6 hari di setiap hari Selasa dan Rabu dari tanggal 22 Oktober 2019 sampai 06 November 2019. Peserta pelatihan adalah siswa IPA dan IPS kelas XI dan XII dengan jumlah kelas sebanyak 8 kelas dan rata-rata jumlah siswa per kelas sebanyak 20 orang. Pelatihan ini diselenggarakan dengan metode pengajaran berbasis teori dan praktik yang langsung dikerjakan oleh peserta pelatihan di setiap sesi pelatihan. Materi yang disampaikan adalah pengenalan Arduino, teori dasar elektronika, perintah IF dan IFELSE, perintah WHILE dan FOR dan ARRAY. Setiap kelas dibagi menjadi 4 kelompok dan masing-masing kelompok diberikan perlengkapan Arduino dan didampingi oleh instruktur dari Fakultas Sains dan Teknologi Universitas Buddhi Dharma. Setiap kegiatan per harinya dapat dilihat di Tabel 1.

Dalam pertemuan terakhir dari pelatihan ini, peserta diberikan quiz secara online untuk mencari grup terbaik yang paling memahami terori yang diberikan. Selain itu, peserta juga di uji dalam quiz praktik untuk menilai kemampuan praktik peserta dalam pengembangan dan modifikasi pemograman Arduino. Dalam tahap akhir, peserta diminta untuk mengisi kuesioner feedback yang juga diisi secara online dan digunakan sebagai acuan evaluasi hasil pelatihan yang diselenggarakan. Angket survei yang digunakan dibuat khusus untuk kegiatan pengabdian masyarakat ini dengan pertanyaan-pertanyaan yang disusun oleh seluruh anggota tim pelaksana kegiatan pengabdian kepada masyarakat di SMA Perguruan Buddhi Tangerang. Angket ini dibagikan setelah pelatihan selesai dilangsungkan di setiap kelasnya pada pertemuan terakhir. Siswa dipandu untuk mengisi form melalui google form dan hasilnya divalidasi dengan membandingkan data sesuai jumlah peserta yang mengikuti pelatihan ini. 
Tabel 1. Rincian kegiatan pelatihan

\begin{tabular}{|c|c|c|c|}
\hline Hari/Tanggal & Peserta pelatihan & Materi & Metode \\
\hline $\begin{array}{c}\text { Selasa, } \\
\text { 22/10/2019 }\end{array}$ & $\begin{array}{l}\text { Kelas XI IPA } 1 \text {, } \\
\text { IPA } 2, \text { IPS } 1 \text { dan } \\
\text { IPS } 2\end{array}$ & $\begin{array}{l}\text { Dasar elektronika dan } \\
\text { rangkaian } 1\end{array}$ & Teori dan praktik \\
\hline $\begin{array}{l}\text { Rabu, } \\
\text { 23/10/2019 }\end{array}$ & $\begin{array}{l}\text { Kelas XII IPA } 1 \text {, } \\
\text { IPA } 2 \text {, IPS } 1 \text { dan } \\
\text { IPS } 2\end{array}$ & $\begin{array}{l}\text { Dasar elektronika dan } \\
\text { rangkaian } 1\end{array}$ & Teori dan praktik \\
\hline $\begin{array}{l}\text { Selasa, } \\
29 / 10 / 2019\end{array}$ & $\begin{array}{c}\text { Kelas XI IPA } 1 \text {, } \\
\text { IPA 2, IPS } 1 \text { dan } \\
\text { IPS } 2\end{array}$ & $\begin{array}{l}\text { IF, IF-ELSE dan } \\
\text { rangkaian } 2\end{array}$ & Teori dan praktik \\
\hline $\begin{array}{l}\text { Rabu, } \\
\text { 30/10/2019 }\end{array}$ & $\begin{array}{l}\text { Kelas XII IPA } 1 \text {, } \\
\text { IPA } 2 \text {, IPS } 1 \text { dan } \\
\text { IPS } 2\end{array}$ & $\begin{array}{l}\text { IF, IF-ELSE dan } \\
\text { rangkaian } 2\end{array}$ & Teori dan praktik \\
\hline $\begin{array}{l}\text { Selasa, } \\
05 / 11 / 2019\end{array}$ & $\begin{array}{c}\text { Kelas XI IPA } 1 \text {, } \\
\text { IPA 2, IPS } 1 \text { dan } \\
\text { IPS } 2\end{array}$ & $\begin{array}{l}\text { WHILE, FOR, } \\
\text { ARRAY dan } \\
\text { rangkaian } 3\end{array}$ & Teori dan praktik \\
\hline $\begin{array}{l}\text { Rabu, } \\
06 / 11 / 2019\end{array}$ & $\begin{array}{l}\text { Kelas XII IPA } 1 \text {, } \\
\text { IPA } 2, \text { IPS } 1 \text { dan } \\
\text { IPS } 2\end{array}$ & $\begin{array}{c}\text { WHILE, FOR, } \\
\text { ARRAY dan } \\
\text { rangkaian } 3\end{array}$ & Teori dan praktik \\
\hline
\end{tabular}

\section{HASIL, PEMBAHASAN, DAN DAMPAK}

Hasil kuesioner yang diisi oleh peserta menunjukkan bahwa pelatihan ini bisa dikategorikan berhasil dalam memicu minat peserta untuk belajar dalam bidang sistem otomasi. Gambar 1 menunjukkan berbagai respon yang diberikan oleh peserta pelatihan dalam menjawab pertanyaan yang diberikan.

Apakah kamu pernah belajar Arduino sebelumnya?

151 responses

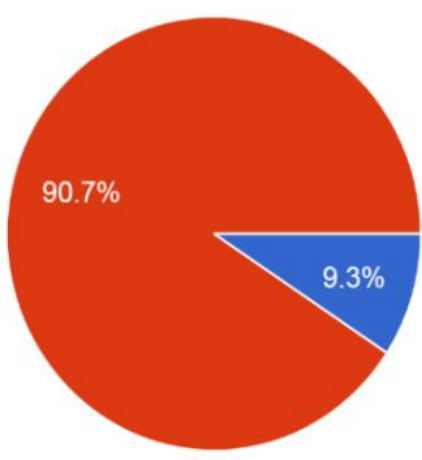

Belum

(a) 


\section{Apakah materi yang disampaikan menarik?}

\section{1 responses}

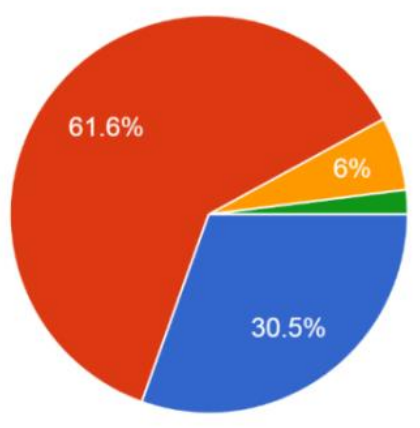

Sangat menarik

Menarik

Kurang menarik

Tidak menarik

(b)

\section{Apakah materi yang disampaikan bermanfaat? \\ 152 responses}

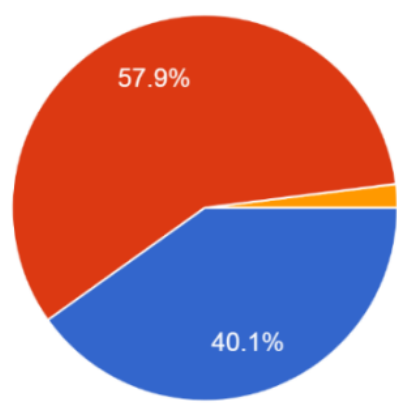

Sangat bermanfaat

Bermanfaat

Kurang bermanfaat

Tidak bermanfaat

(c)

Gambar 1. Jawaban seluruh peserta pelatihan terhadap berbagai pertanyaan yang diberikan. Pertanyaan untuk mengukur pengtahuan sebelumnya terkait Arduino (a), pertanyaan untuk mengukur daya tarik materi yang disampaikan (b) dan pertanyaan untuk mengukur manfaat materi yang diberikan (c)

Dari Gambar 1, kita bisa melihat bahwa Arduino masih merupakan hal baru untuk peserta. Tapi, mayoritas peserta mengganggap bahwa materi yang disampaikan menarik untuk diperlajari. Selain itu, mayoritas peserta juga menjawab bahwa pelatihan ini bermanfaat untuk mereka.

Kami juga memberikan survei terpisah yang diisi oleh hanya mahasiswa dengan jurusan IPS. Hal ini dilakukan untuk melihat seberapa besar minat mereka untuk mempelajari bidang sistem otomasi jika diberikan kesempatan untuk mempelajarinya. Hasil kuesioner yang diisi oleh pelajar dari jurusan IPS bisa dilihat di Gambar 2. 
Apakah kamu pernah belajar Arduino sebelumnya?

72 responses

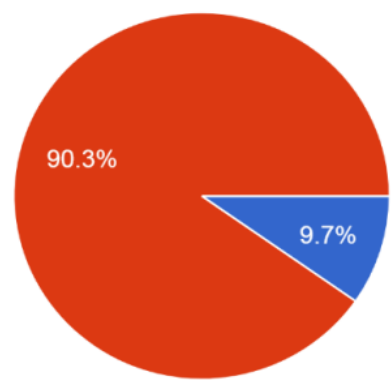

(a)

Apakah materi yang disampaikan menarik?

72 responses

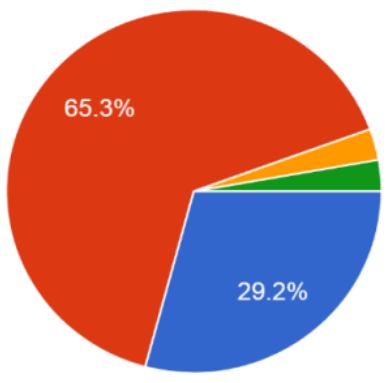

Sangat menarik

Menarik

Kurang menarik

Tidak menarik

(b)

\section{Apakah materi yang disampaikan bermanfaat?}

72 responses

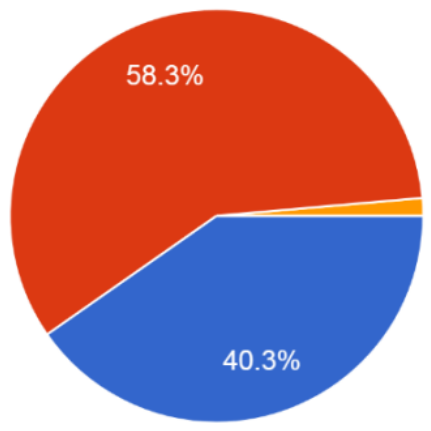

Sangat bermanfaat

Bermanfaat

Kurang bermanfaat

Tidak bermanfaat

(c)

Gambar 2. Hasil kuesioner yang dijawab oleh peserta dengan latar belakang jurusan IPS. Pertanyaan untuk mengukur pengetahuan sebelumnya terkait Arduino (a), pertanyaan untuk mengukur daya tarik materi yang diberikan (b) dan pertanyaan untuk mengukur manfaat materi yang disampaikan (c) 
Secara mengejutkan, kami menemukan bahwa peserta dengan jurusan IPS tidak kalah antusias dengan peserta dari jurusan IPA. Mayoritas peserta dari jurusan IPS juga menjawab bahwa pelatihan ini menarik dan bermanfaat. Untuk itu, tidak menutup kemungkinan jika ada mahasiswa IPS yang tertarik untuk lebih dalam mempelajari bidang sistem otomasi di masa depan.

Gambar 3 menunjukkan aktivitas pelatihan selama diselanggarakan dan kami juga mengamati bahwa mayoritas peserta pelatihan terlihat antusias selama pelatihan baik dalam sesi penjelasan teori maupun dalam sesi praktik.

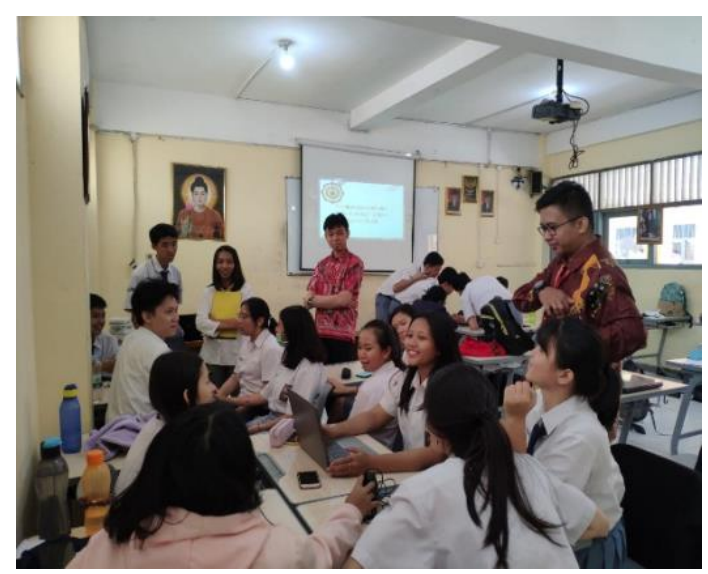

(a)

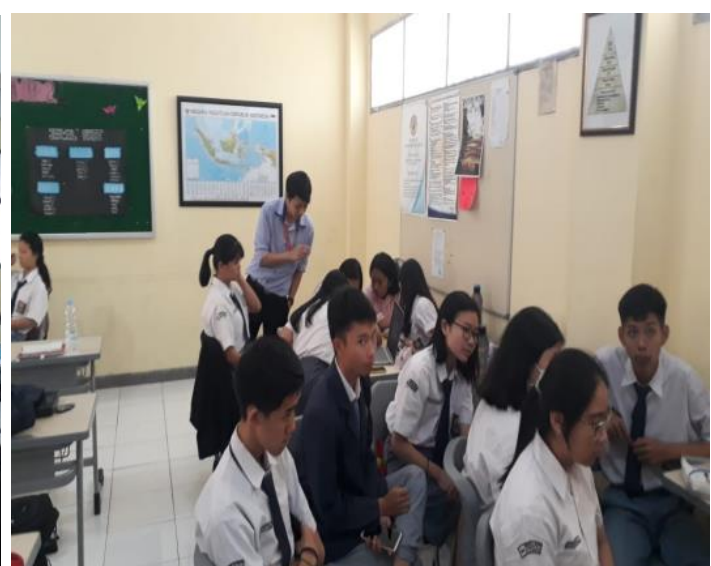

(b)

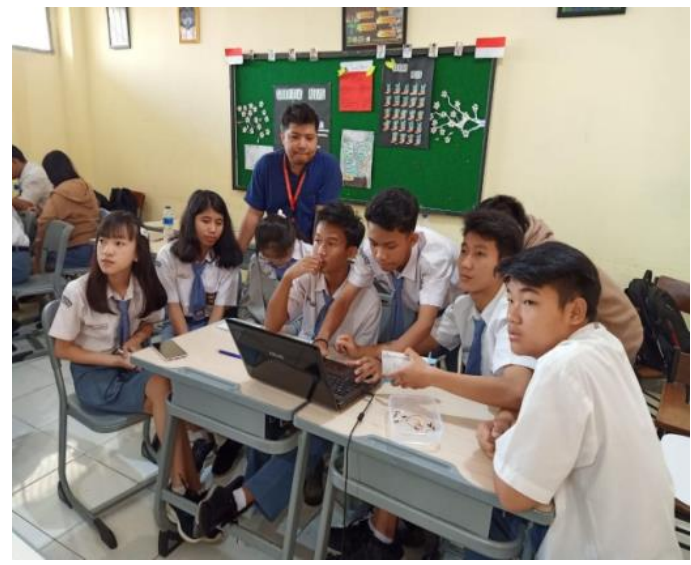

(c)

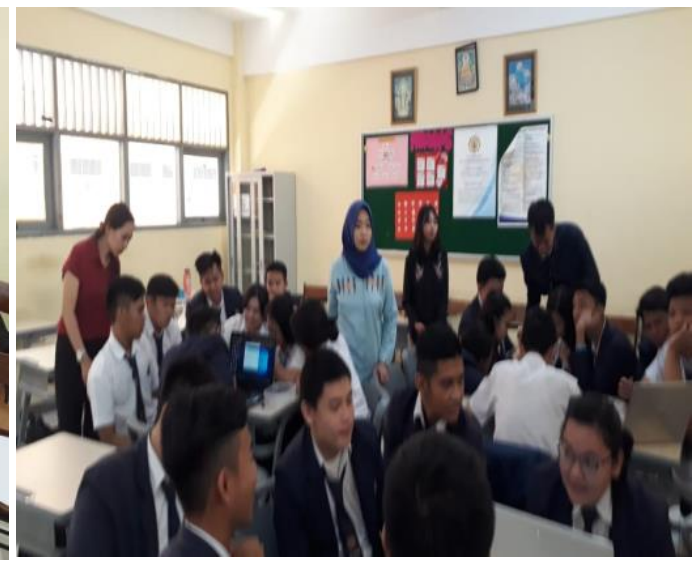

(d)

Gambar 3. Aktivitas selama pelatihan dimana (a) dan (b) menunjukkan kondisi saat persiapan pelaksanaan pelatihan sementara (c) dan (d) menunjukkan kondisi selama praktik berlangsung.

\section{SIMPULAN}

Pelatihan ini berhasil memicu minat siswa untuk mempelajari bidang sistem otomasi. Siswa juga menikmati proses belajar yang tidak hanya melibatkan komponen teori tapi juga komponen praktik. Sistem quiz secara online juga dapat meningkatkan daya tarik peserta pelatihan dalam menjawab pertanyaan-pertanyaan yang diberikan. Siswa dengan latar belakang jurusan IPS ditemukan tidak kalah antusias dengan siswa dengan jurusan IPA. Diharapkan agar pelatihan ini dapat diterapkan di sekolah lain dan jika dimungkinkan agar pelajaran ini bisa secara rutin dipelajari ditingkat sekolah menengah. 


\section{UCAPAN TERIMAKASIH}

Tim pelaksana kegiatan pengabdian kepada masyarakat mengucapkan terima kasih kepada kepala sekolah SMA Perguruan Buddhi beserta para guru yang telah mendukung terlaksananya kegiatan ini. Kami juga berterima kasih terhadap dukungan finasial yang diberikan Universitas Buddhi Dharma untuk kegiatan ini.

\section{DAFTAR PUSTAKA}

Boulogne, F. (2019). Cheap and versatile humidity regulator for environmentally controlled experiments. The European Physical Journal E, 42(4), 51.

Martín-Ramos, P., Lopes, M. J., da Silva, M. M. L., Gomes, P. E., da Silva, P. S. P., Domingues, J. P., \& Silva, M. R. (2018). Reprint of 'First exposure to arduino through peer-coaching: Impact on students' attitudes towards programming'. Computers in Human Behavior, 80, 420-427.

Sai, D. Y. V., Kiran, C. S., Samson, B., Kumar, B. S., \& Raju, C. G. (2019). IoT based environment monitoring by using arduino. International Journal of Scientific Research in Computer Science Engineering and Information Technology, 5(2), 717-720.

Shruthi, K., \& Akhil, G. (2019). Arduino-based smart street lamp control system to save energy and improve lamp life. In Saini H., Singh R., Patel V., Santhi K., \& Ranganayakulu S (Eds.), Innovations in electronics and communication engineering (pp. 131-141). Springer.

Wong, W. K., Guo, B. S., Chao, T. K., Wu, C. J., \& Lien, Y. W. (2018). A study of high school students doing physics experiments with arduino and other data-logging devices. In Li K., Yuen K., \& Wong B. (Eds.), Innovations in open and flexible education (pp. 253-264). Springer. 
